ISSN 1983-8484

Licenciado sob uma Licença Creative Commons

\title{
O aroma como componente de geração de valor de marca de varejo
}

\author{
The aroma as a key brand value for retail
}

Ana Carolina Coe Torres ${ }^{[a]}$, Cláudia Buhamra ${ }^{[b]}$

[a] Mestre em Administração e Controladoria pela Universidade Federal do Ceará (UFC), professora titular da Associação do Ensino Superior do Piauí e do Centro de Ensino Superior do Vale do Parnaíba, Teresina, PI - Brasil, e-mail: anacarolinacoe@gmail.com

[b] Doutora em Administração pela Fundação Getúlio Vargas (FGV), professora associada Faculdade de Economia, Administração, Atuária e Contabilidade da Universidade Federal do Ceará, Fortaleza, CE - Brasil, e-mail: buhamra@ufc.br

\section{Resumo}

0 presente estudo teve por objetivo investigar se o aroma, como parte integrante de marca de varejo, contribui para a geração do constructo valor de marca, através do reconhecimento e da lembrança espontânea da marca. Foi realizada uma pesquisa em duas fases: a primeira, de cunho exploratório e qualitativo, realizada com o proprietário da MMartan, loja de varejo de atuação nacional, do segmento de cama, mesa e banho, que já trabalha com a estratégia de marketing olfativo. A segunda fase da pesquisa, descritiva e quantitativa, foi realizada dentro do shopping center onde a loja está localizada, com 146 pessoas, na cidade de Fortaleza. Na primeira fase, foram investigadas as sensações e emoções que a direção da loja desejava estimular nas pessoas quando idealizou o aroma como um dos componentes da sua marca. Na segunda fase, avaliou-se se o aroma gerava lembrança de marca e provocava as sensações pretendidas pela direção da empresa. Os resultados foram negativos para os que não frequentavam a loja. Entretanto, entre os entrevistados que conheciam, frequentavam a loja e lá compravam, 81\% identificaram a marca da loja através do aroma e expressaram sensação de prazer, evidenciando o aroma como gerador de valor da marca.

Palavras-chave: Marca. Valor. Marketing de experiência. Marketing olfativo.

\section{Abstract}

This study aimed to investigate whether the aroma, as part of the retail brands, contributes to the creation of brand value, through recognition and recall. A survey was performed in two phases: (i) exploratory and qualitative, conducted with the owner of MMartan, a national retail store that already works with the aroma marketing strategy; and (ii) descriptive quantitative, was held in a shopping center, with 146 people, in the city of Fortaleza. In the first phase, it was analyzed the feelings and emotions that the store desired to stimulate on persons when the aroma was defined as a component of the brand. In the second phase, it was evaluated if the aroma produced brand recall and provoked the feelings that the store wanted to stimulate. The results were negative to the people that didn't frequent 
the store. However, between the interviewers that knew and frequented the store, $81 \%$ identified the store brand through the aroma and expressed pleasure sensation, proving the aroma as a brand value producer.

Keywords: Brand. Value. Experience marketing. Olfactory marketing.

\section{Introdução}

Este trabalho versa sobre a mudança gradual no que se conhecia sobre marca, como sendo apenas um símbolo de identificação de produtos e ou serviços, para um novo conceito que poderá não apenas ser embasado na repetição das antigas técnicas de propaganda, como a criação de peças publicitárias para a grande massa ou a realização de promoções, cujas ações eram executadas individualmente, sem a preocupação com a unidade conceitual da mensagem e da sua interação com o público-alvo.

Poderá sim, acima de tudo, assumir, além de uma postura sinérgica, em que todas as formas de comunicação transmitem uma única mensagem, maximizando o seu impacto, também uma postura sinestésica, onde buscará envolver seus clientes em uma atmosfera capaz de aguçar todos os sentidos humanos, gerando experiências positivas com a marca, aplicando o conceito de marca multissensorial.

Observando e analisando essas mudanças, as lojas de varejo começaram a utilizar essas novas estratégias sensoriais com o intuito de conseguir atingir seus clientes de uma maneira mais emotiva, que instigue os sentidos e gere experiências positivas.

Assim, tendo o olfato como um sentido que agora começa a ganhar espaço dentro das ações de comunicação devido, segundo Lindstrom (2007), à sua capacidade de ser um importante instrumento na evocação da memória, tratando diretamente o lado emocional das pessoas, remetendo-as a um passado distante, o presente estudo analisa os benefícios advindos da aplicação dessas estratégias sensoriais, a partir de suas associações com o constructo valor de marca. Conforme Tavares (2008), o valor de marca pode ser analisado sob a perspectiva das organizações e sob a perspectiva do consumidor, sendo essa última considerada a responsável sobre o real significado desse constructo.

Essa afirmação baseia-se no fato de que os clientes percebem valor em uma marca a partir de seus conhecimentos sobre a própria, sobre seu reconhecimento com relação a outras mensagens, atributos, benefícios e associações, além da sua lembrança espontânea.

Keller (2006) menciona que valor de marca ocorre quando o cliente possui um elevado nível de lembrança de marca e familiaridade com a mesma e a mantém em sua memória por meio de fortes associações, gerando exclusividade através da imagem de marca. A lembrança de marca é constituída pelo desempenho do reconhecimento da marca e da lembrança espontânea da marca. Segundo Keller (2006), reconhecimento de marca é a capacidade dos consumidores de identificarem corretamente uma marca que já viram ou ouviram anteriormente. E lembrança espontânea de marca é a capacidade dos consumidores de extraírem de suas mentes uma determinada marca quando lhes é sugerida a categoria de um produto. Para tanto, o presente artigo objetiva investigar se o aroma, como parte integrante de marca de varejo, contribui para a geração de valor da marca.

0 presente artigo foi desenvolvido a partir de uma revisão integrativa (integrative review) que buscou ratificar algumas proposições e ao mesmo tempo encontrar subsídios para desenvolver um conteúdo relevante para as pesquisas acerca do tema marcas olfativas. A partir da reunião e leitura de livros e artigos (LINDSTROM, 2007; MOORE, 2004; SCHMITT; SIMONSOM, 2002; ZAREM, 2000), foram selecionados aqueles que apresentam argumentos mais substanciais sobre o tema escolhido e poderiam melhor embasar a pesquisa de campo.

Com a finalidade de atingir o objetivo geral deste estudo, que é o de investigar se o aroma, como componente integrante de marca de varejo, gera valor de marca, fundamentada em Malhotra (2006), a pesquisa foi divida em duas fases. Na primeira, exploratória e qualitativa, foram utilizados métodos de levantamento de dados bibliográficos e estudo de caso. $\mathrm{Na}$ segunda, foi realizada pesquisa descritiva e quantitativa, com a coleta de dados primários, através da aplicação de 146 questionários semiestruturados. Maiores detalhes sobre a pesquisa são expostos no item 6, que trata da Metodologia. 
A marca como geradora de experiências

Fazer marketing está se tornando cada vez mais difícil. Não adianta apenas conhecer e buscar atender ou incitar desejos latentes nos consumidores. É preciso saber exatamente para quem oferecer, como oferecer, quando oferecer e, principalmente, como aparecer. Em meio a essa grande quantidade de comunicações, impactar o público-alvo deixou de ser uma tarefa meramente de exposição das qualidades, funções e benefícios de um produto, para se tornar em uma ação de envolvimento.

"Hoje, os consumidores desejam não somente os produtos, mas experiências que satisfaçam à sua necessidade. Estas experiências devem proporcionar aos consumidores entretenimento, para que estes aproveitem seu escasso tempo livre em atividades de lazer" (SALAZAR; FARIAS, 2006, p. 4).

Agora, o consumidor efetiva sua compra, cada vez menos, através da análise de benefícios e atributos de um produto associados a uma marca e mais pelas experiências proporcionadas a partir do processo de compra (LELO et al., 2007). A partir de então, a decisão de compra deixa de ser um processo racional para se tornar emocional. Assim, os antigos conceitos e técnicas de marketing estão se tornando obsoletos, abrindo espaço para novas possibilidades. Logo, o uso das marcas como possíveis geradoras de experiências (marketing de experiência), de percepções sensoriais (marketing de sentidos) e de sensações olfativas (marketing olfativo) surge como uma das possíveis soluções para essa mudança no mercado.

\section{Marketing de experiências}

Schmitt (2002) menciona que o marketing está surgindo com uma abordagem totalmente nova em detrimento do marketing tradicional. Esse fato desenvolve-se sob três fenômenos: a) a onipresença da tecnologia; b) a supremacia da marca e; c) a ubiquidade das comunicações integradas e do entretenimento.

0 primeiro fenômeno é descrito como um mundo tomado pelas novas tecnologias, onde tudo o que puder ser digitalizado será. Um mundo onde a tecnologia busca novas maneiras de se integrar à vida humana e onde o desenvolvimento tecnológico ocasionará na conexão e compartilhamento de experiências por quaisquer pessoas ou empresas e a qualquer momento. Isso muda a percepção voltada apenas para as diferenciações técnicas ou funcionais, que, como apresentado, podem ser facilmente disseminadas e/ ou até copiadas.

Influenciadas por esses avanços tecnológicos, as marcas significarão praticamente tudo, elas estarão presentes em todos os meios de comunicação, desde panfletos, jornais, mídia exterior a telas de cinema. Portanto, sua supremacia ocasiona num cuidado maior com a sua exposição e em como ela consegue se destacar no mercado, tendo em vista que "nesse universo de domínio das marcas, os produtos deixam de ser pacotes de características funcionais e passam a ser meios para fornecer e melhorar as experiências para o consumidor" (SCHMITT, 2002, p. 26).

0 último fenômeno que auxilia na revolução dos conceitos de marketing está embasado na onipresença também da comunicação, já que, como tudo está se tornando uma marca, as empresas, produtos e serviços logo se transformarão em uma forma de comunicação ligada à marca. Além disso, a comunicação deixa de ter um caráter apenas informativo para se tornar entretenimento (SCHMITT, 2002).

Assim, o marketing experiencial, segundo Schmitt (2002), baseia-se em quatro características básicas, que são: a) foco nas experiências do consumidor, considerando experiência como o resultado de encontros e vivências, gerando valores sensoriais, emocionais, cognitivos, comportamentais e de identificação; b) preocupação com a situação de consumo e não apenas com a restrição de categorias; c) visão de consumidores racionais e emocionais, que buscam além dos fatores funcionais, entretenimento, emoções, estímulos e desafios criativos; e d) utiliza de ferramentas diversificadas e multifacetadas para encontrar boas ideias.

Zarem (2000) comenta a importância do marketing experimental mencionando a dificuldade por parte das empresas em se destacar no mercado através apenas de preços. Agora, por acreditarem que experiências positivas e agradáveis podem se tornar pontos significativos no processo de decisão de compra do consumidor, resultando em maior fidelidade, as empresas estão buscando, cada vez mais, trabalhar com o marketing de experiências.

\section{Marketing olfativo}

Atualmente, várias empresas estão, propositalmente, perfumando seus ambientes como uma 
estratégia de chamar a atenção dos transeuntes que passam em frente às lojas e sentem um maravilhoso perfume, fazendo com que associem a fragrância à marca, sintam-se atraídos pela vitrine e, por fim, entrem no estabelecimento (NUCCI, 2006).

Dessa forma, continuando o processo de busca por diferenciação de mercado por meio do uso de técnicas de marketing experiencial e de marketing sensorial, chega-se agora, mais detalhadamente, a aplicação do aroma também como ferramenta de auxílio ao destaque de produtos e serviços no mercado.

Logo, com o intuito de chamar mais atenção, os profissionais de marketing estão considerando o uso do aroma como uma possibilidade de se diferenciar nesse concorrido mercado, tendo em vista que o processo olfativo tem a capacidade de armazenar até 10 mil aromas, além de levar apenas $1 / 3$ de segundo para gerar uma resposta ao cérebro (DONNICI, 2005).

Mas por que o olfato? Por que não usar o tato ou mesmo o paladar? Algumas dessas justificativas podem ser percebidas mediante características fisiológicas do próprio sentido olfativo. Uma delas, segundo Strugnell e Jones (1999 apud CARNEIRO, 2009), diz que o corpo humano possui no epitélio olfativo entre 6 a 10 milhões de células receptoras e que podem reconhecer de 2 mil a 4 mil aromas diferentes. Outro fato muito interessante é o de que todo e qualquer objeto emite moléculas de odor flutuantes no ar.

O sistema olfativo é capaz de identificar uma grande lista de cheiros que cercam os homens diariamente. No mundo existem por volta de $100 \mathrm{mil}$ odores, uma grande parcela deles denominado de primários, responsáveis por influenciar o humor e o comportamento humano, e que formam uma grandiosa quantidade de novas combinações de múltiplos odores. Geralmente, os aromas podem ser divididos em 7 categorias distintas: (1) cítricos, (2) florais, (3) resinosos, (4) desagradáveis, (5) almiscarados, (6) sutis e (7) acres (LINDSTROM, 2007; SCHMITT; SIMONSOM, 2002).

Apesar de todos notarem esses cheiros, as percepções são diferentes para cada pessoa, tendo em vista a intervenção de variáveis, como gênero, idade e raça. Pesquisas já comprovaram que alguns aromas parecem ser uniformes quanto à atração e desaprovação, bem como a reação das mulheres é diferente da reação masculina no que diz respeito a determinados aromas (LINDSTROM, 2007; SCHMITT; SIMONSOM, 2002).
No campo acadêmico, Carneiro (2009) mostra que, dentre os estudos relacionados ao trabalho com estímulos ambientais, o uso do aroma vem se sobressaindo como o forte influenciador do comportamento humano, de suas emoções e cognições. Moore (2004) menciona que, apesar de algumas competentes pesquisas de marketing já trabalharem com o olfato, são poucas as pesquisas formais que analisam a influência do aroma no comportamento do consumidor, em especial, relacionado a comidas. Mais difícil ainda é encontrar pesquisas que relacionem a percepção do aroma como componente integrante de uma marca e sua influência no processo de lembrança dessa marca.

Em meio a essa enxurrada de questionamentos e pesquisas acerca do uso do aroma como mais uma técnica a ser trabalhada pelo mundo mercadológico e com o objetivo de conquistar cada vez mais os consumidores, nasce o marketing olfativo. Proveniente do marketing emotivo, busca chegar às profundezas do cérebro humano, convencido de que tudo possui aroma (MARKETING, 2008).

Perez (2007) diz que o marketing olfativo busca consolidar, conquistar e aumentar a simpatia pelo produto ou empresa, resultando na memorização dos produtos a partir de suas associações a emoções agradáveis produzidas pelo cheiro. Flôr e Umeda (2008) o tem definido como as práticas adotadas por empresas, em especial pelo setor varejista, que buscam associações entre marcas ou produtos com aromas, e que tem por objetivo incitar o desejo dos seus prováveis clientes. Os mesmos autores continuam afirmando que essa técnica objetiva criar, assim como os processos de criação de uma logomarca visual, uma identidade olfativa.

Em Simões (2008), vê-se que "uma boa composição olfativa é capaz de atrair a atenção do cliente, podendo aumentar o tráfego no estabelecimento, a velocidade de visitação, o tempo de permanência dentro da loja, despertar a fome e até a libido".

Segundo Carneiro (2009), com frequência os varejistas, em virtude da ideia de que os clientes terão que 'ver' e 'ouvir' necessariamente, consideram os estímulos visuais e auditivos como os mais relevantes. Outros estímulos percebidos através dos sentidos como olfato e paladar não têm ganhado a devida atenção. A maioria das corporações baseia sua identidade apenas a partir da imagem (logomarcas, comunicação visual, patrocínios) e no som (música de fundo em lojas ou melodias de seus comerciais) (MARKETING, 2008). 
Contudo, esses mesmos varejistas vêm percebendo que o processamento do aroma por parte dos consumidores já está recebendo mais atenção. Uma das possíveis explicações está no fato de que o aroma pode agir sobre os clientes sem que esses mesmos o notem, além disso, o homem tem a capacidade de reconhecê-lo por meio de diversos níveis (DAVIES; KOOIJMAN; WARD, 2003). Dessa forma, os comerciantes podem influenciar seus possíveis clientes sem que eles percebam que estão sendo envolvidos por esses estímulos.

Segundo Carneiro (2009), o aroma influencia subliminarmente o comportamento humano, pois consegue atingir diretamente as suas emoções, impactando fortemente nas vendas. Outra importante característica que reforça o uso do aroma em ambientes de varejo é a sua capacidade de gerar uma impressão não fragmentada da loja, onde o consumidor analisa o espaço como um todo e não apenas os seus componentes (CARNEIRO, 2009). Dessa forma, o uso do aroma como peça-chave na composição da identidade e da atmosfera comercial pode fornecer um forte ponto de diferenciação no mercado.

A partir desse pensamento, os varejistas têm em suas mãos uma ferramenta em potencial na construção de uma identidade coerente, clara e consistente (DAVIES; KOOIJMAN; WARD, 2003). Partindo da premissa de que se pode fechar os olhos, cobrir as orelhas, rejeitar o sabor, mas não se pode evitar o cheiro, já que ele faz parte do ar que se respira (LINDSTROM, 2008), os profissionais estão ousando na criação de suas identidades.

Em harmonia com esse pensamento, afirma-se que em meio a uma igualdade de produtos e serviços globalizados, as empresas necessitavam de um diferencial que atingisse o emocional das pessoas. Assim, nasce a identidade olfativa com o objetivo de cumprir plenamente esse papel (SIMÕES, 2008).

Simões (2008) diz que criar uma marca olfativa identificada com a empresa e que consiga despertar o interesse de seus clientes não é algo fácil. É preciso conhecer e estudar o público da empresa que pretende inserir o aroma em sua composição de marca, a partir de uma análise da faixa etária, da origem e dos hábitos dos consumidores, relacionando-os com os conceitos de marca e produto.

\section{Valor de marca}

A diferenciação no mercado está se tornando cada vez mais difícil. A facilidade de acesso à informação e o surgimento de uma infinidade de novos produtos faz com que a fidelização às marcas torne-se algo quase inatingível. Os consumidores agora estão propensos à experimentação e todos esses pontos incorrem sobre um fato a se questionar: como um produto ou serviço conseguirá se destacar em meio a tanta informação?

A resposta para esse questionamento pode estar em um simples conceito, o de valor de marca ou brand equity, ou ainda, valor patrimonial de marca. De acordo com Oliveira (2006), a sociedade passou da era industrial, que tinha como base os ativos tangíveis, para a era da informação, onde os tópicos relevantes eram o conhecimento e as ideias, isto é, os ativos intangíveis. Na década de 80 , em virtude das fusões e aquisições realizadas, houve a necessidade de se reavaliar o valor patrimonial da marca, considerando agora a participação dos ativos intangíveis na tentativa de se definir financeiramente o valor real de uma empresa (OLIVEIRA, 2006; TAVARES, 2008).

Em meio a essa situação, de fusões e aquisições no ambiente empresarial, Serralvo (2008) diz que foram gerados os modelos de valorização de marcas a fim de buscar explicar o que esses ativos intangíveis poderiam representar de valor econômico. Foram esses ativos intangíveis que reforçaram a preocupação pelo entendimento desse novo conceito.

0 valor de marca pode ser "criado nessas relações da empresa com seu mercado. Ou, ainda, o valor é criado nas relações da marca com seu público ou seus stakeholders, seja ele interno ou externo à empresa" (NUNES; HAIGH, 2003, p. 75). Os mesmos autores afirmam que a principal tarefa para uma boa gestão de marca está na compreensão dessas relações de causa e efeito com o público de uma empresa no que diz respeito ao processo de criação de valor de uma marca e que a medição pode ser aferida mediante a criação de indicadores de desempenho.

0 valor de uma marca pode ser analisado sob duas perspectivas, ou enfocando as organizações ou enfocando os consumidores. Sob a primeira, o valor de marca pode ser visto de uma ótica financeira, sendo considerado um dos ativos da empresa, percebido apenas quando da liquidação desses ativos (TAVARES, 2008). Já Serralvo (2008) busca simplificar quando menciona que a vertente financeira envolve o brand equity sob a perspectiva do valor da marca, ou seja, o valor financeiro dado a ela.

Por valor da marca entende-se como sendo o resultado financeiro da habilidade de geração da 
alavancagem do valor de marca por ações táticas e estratégicas, provendo lucros correntes futuros e superiores aos da concorrência, com riscos mais baixos (SERRALVO, 2008).

Para as organizações, as marcas significam ativos extremamente importantes, que influenciam o comportamento do consumidor, que podem ser compradas e vendidas e fornecer aos seus proprietários a segurança de receitas futuras constantes (KELLER, 2006).

No entanto, Tavares (2008), menciona que o real significado para o conceito de valor de marca está na mente do consumidor, baseando-se em seus conhecimentos sobre a marca, em sua lembrança e no reconhecimento em associá-la a várias mensagens, atributos, benefícios e associações.

As marcas representam mais do que simplesmente a identificação do fabricante e suas responsabilidades perante um produto, elas significam algo muito especial. Por meio de experiências com as marcas, os clientes passam a conhecê-las e, assim, podem reduzir e simplificar seu processo de decisão de compra, descobrindo quais marcas mais os satisfazem e quais não os satisfazem (KELLER, 2006).

Nesse sentido, o valor de marca tem como principal ponto de partida o consumidor, objetivando provocar respostas favoráveis relacionadas à sua distribuição, ao seu preço e a suas ações de promoção (TAVARES, 2008).

Conforme Keller (2006), na perspectiva do consumidor, o brand equity ocorre quando o cliente possui um elevado nível de lembrança de marca e familiaridade com a mesma, além da manutenção, em sua memória, de fortes associações, gerando exclusividade por meio da imagem de marca. De acordo com Keller (2006), a imagem de marca pode ser criada por meio da ligação de fortes, favoráveis e exclusivas associações às marcas na mente do consumidor, geradas a partir de programas de marketing.

Além da imagem da marca, a lembrança da mesma constitui-se no desempenho do reconhecimento de marca e da lembrança espontânea de marca. Por reconhecimento de marca tem-se a capacidade dos consumidores em identificar corretamente uma marca que já viram ou ouviram anteriormente. E por lembrança espontânea de marca tem-se a capacidade dos consumidores em extrair de suas mentes uma determinada marca quando lhes são sugeridas a categoria de um produto (KELLER, 2006).

\section{Metodologia}

Com a finalidade de atingir o objetivo geral deste estudo, que é o de investigar se o aroma, como componente integrante de marca de varejo, gera valor de marca, tendo por base a revisão teórica levantada, foram propostos os seguintes pressupostos:

I) 0 aroma estimula a lembrança espontânea de marca.

II) 0 aroma gera reconhecimento da marca de loja de varejo.

Fundamentada em Malhotra (2006), a pesquisa foi divida em duas fases. Na primeira fase, trabalhou-se com uma pesquisa de caráter exploratório e qualitativo, utilizando como métodos o levantamento de dados bibliográficos e o estudo de caso selecionado, por meio de uma entrevista pessoal e em profundidade, realizada no dia 15 de dezembro de 2009, às $15 \mathrm{~h}$, com o proprietário de uma das franquias da loja de cama, mesa e banho MMartan, situada na Avenida Dom Luiz, na cidade de Fortaleza. A escolha por essa loja deve-se ao fato de ser uma empresa já consolidada no mercado em nível nacional e por já atuar há mais de 25 anos no segmento, além de já possuir sua marca olfativa e de ser de fácil acesso do pesquisador.

Na segunda fase, trabalhou-se com uma pesquisa descritiva e quantitativa, utilizando apenas dados primários. Através da aplicação de 146 questionários semiestruturados, aplicados dentro da área de cinema do Shopping Iguatemi da cidade de Fortaleza, isto é, com alto índice de rotatividade e frequência. Não sendo possível recolocar um dado elemento novamente na seleção da amostra, utilizou-se uma amostra não probabilística, intencional, por conveniência. Os sujeitos da pesquisa foram homens e mulheres, acima de 16 anos, transeuntes do Shopping Iguatemi e que, durante os últimos seis meses que antecederam a pesquisa, frequentaram ou compraram em lojas do Shopping, exceto lojas de alimentação e diversão.

Antes da realização final do questionário, foram aplicados dois pré-testes. 0 primeiro pré-teste foi realizado no dia 17 de novembro de 2009, por conveniência, com sete pessoas próximas do pesquisador. 0 segundo pré-teste foi realizado no dia 8 de janeiro de 2010 , das $14 \mathrm{~h}$ às $17 \mathrm{~h}$, na área de cinema do Shopping Iguatemi, com 32 pessoas. 
0 questionário final da pesquisa foi formado por perguntas de classificação, de opinião, e abertas e fechadas, e foi aplicado por dois entrevistadores na área de compra de ingressos do cinema UCI Ribeiro do Shopping Iguatemi, no dia 13 de janeiro de 2010. A pesquisa aconteceu da seguinte forma: primeiro o entrevistador abordava um possível entrevistado, apresentava-se e perguntava se poderia dar início à entrevista. Com o aval do entrevistado, o entrevistador solicitava que fosse sentido o aroma de sementes de café, as quais têm reconhecido poder de apurar o sentido olfativo, neutralizando outros aromas.

A partir de então, seguiu-se a pesquisa, divida em três momentos. No primeiro, o espontâneo, após sentir a fragrância, foram feitas perguntas sobre a avaliação do aroma e se o entrevistado o identificava como sendo próprio de alguma loja. No momento estimulado, o entrevistador mostrou, em forma de cartão, algumas marcas presentes no Shopping, dentre elas a marca da loja MMartan, e perguntou ao entrevistado se ele fazia a associação do aroma apresentado a algumas daquelas lojas.

Por fim, no induzido, após o entrevistado não ter conseguido fazer a correta associação, o entrevistador afirmou que o aroma era da loja MMartan, dando prosseguimento ao questionário fazendo perguntas, tais como: se ele conhecia a loja, se já a havia frequentado, e quantas vezes nos últimos seis meses. Após essas fases, foi também questionado que sensações e sentimentos eles associavam ao aroma apresentado, finalizando com as perguntas sobre o perfil do entrevistado.

0 questionário foi aplicado seguindo alguns processos-padrão, tais como: o tempo entre a borrifação e o ato do entrevistado sentir o aroma durou, em média, 30 segundos; a distância equivalente entre a mão do entrevistador e a etiqueta olfativa (o papel utilizado para sentir a fragrância) era de, mais ou menos, 12,5 centímetros; e para a aplicação de cada questionário, trabalhou-se, em média, de 5 a 8 minutos.

\section{Análise e discussão dos resultados}

Com a finalidade de analisar se o aroma, aplicado em lojas de varejo, gera valor de marca, foram estudadas duas variáveis: lembrança espontânea e reconhecimento de marca. Por lembrança espontânea, foi considerada a correta associação do aroma apresentado à marca na fase espontânea, e na fase estimulada, considerou-se como sendo reconhecimento de marca.

Assim, dos 146 entrevistados na fase espontânea, 82 pessoas, isto é, $56 \%$, afirmaram reconhecer o aroma apresentado como sendo de alguma loja (Quadro 1). Quando perguntados com quais lojas os

Quadro 1 - Número e percentual de pessoas que reconheceram o aroma como sendo de alguma loja

\begin{tabular}{lcc}
\hline Alternativas & Frequência & $\%$ \\
\hline Sim & 82 & 56 \\
Não & 64 & 44 \\
Total & 146 & 100 \\
\hline
\end{tabular}

Fonte: Dados da pesquisa.

Quadro 2 - Lojas citadas no Quadro 1

\begin{tabular}{|c|c|c|}
\hline Lojas & Frequência & $\%$ \\
\hline MMartan & 20 & 25 \\
\hline Loja de perfume & 8 & 10 \\
\hline Renner & 6 & 8 \\
\hline Água de Cheiro & 5 & 6 \\
\hline$C \& A$ & 5 & 6 \\
\hline Ganz & 4 & 5 \\
\hline Loja Indiana & 4 & 5 \\
\hline Handara & 3 & 4 \\
\hline Boticário & 2 & 2 \\
\hline Brans'k & 2 & 2 \\
\hline Essential Parfums & 2 & 2 \\
\hline Taco & 2 & 2 \\
\hline Tentacion & 2 & 2 \\
\hline Animale & 1 & 1 \\
\hline Casa de chás & 1 & 1 \\
\hline Colmeia & 1 & 1 \\
\hline Liebe & 1 & 1 \\
\hline Zefirelli & 1 & 1 \\
\hline NS/NR & 12 & 16 \\
\hline Total & 82 & 100 \\
\hline
\end{tabular}

Fonte: Dados da pesquisa. 
entrevistados faziam essa associação, os resultados foram os obtidos no Quadro 2.

Observando os dados, pode-se inferir que, dos 82 que reconheceram o aroma como sendo de alguma loja, 20 desses, na fase espontânea, conseguiram associá-lo corretamente à marca MMartan, o que representa um total de $14 \%$ de lembrança de marca, levando em consideração os 146 entrevistados (Quadro 3) e de $25 \%$ com relação aos 82 que reconheceram o aroma como sendo de alguma loja. Desses 20, entre os homens e mulheres que reconheceram o aroma, 17 (85\%) já frequentaram a loja MMartan e apenas

Quadro 3 - Número e percentual de pessoas que reconheceram o aroma na fase espontânea

\begin{tabular}{lcc}
\hline Alternativas & Frequência & $\%$ \\
\hline Sim & 20 & 14 \\
Não & 126 & 86 \\
Total & 146 & 100 \\
\hline
\end{tabular}

Fonte: Dados da pesquisa.

Quadro 4 - Reconheceu o aroma na fase espontânea e frequentou a loja MMartan

\begin{tabular}{lcc}
\hline Alternativas & Frequência & $\%$ \\
\hline Sim & 17 & 85 \\
Não & 3 & 15 \\
Total & 20 & 100 \\
\hline
\end{tabular}

Fonte: Dados da pesquisa.

$3(15 \%)$ ainda não a tinham frequentado, embora tivessem reconhecido o aroma (Quadro 4).

Dos 17 que haviam frequentado a loja, 15 também compraram na MMartan. Os $12 \%$ que não compraram ainda representam um dado interessante, já que também associaram corretamente o aroma à marca (Quadro 5).

Partindo agora para a fase estimulada da pesquisa, dos 126 que responderam que associavam o aroma a algumas das lojas apresentadas no cartão, 91 (72\%) disseram que faziam a associação e 35 (28\%) passaram para a fase induzida, como mostra o Quadro 6. 0 ranking das lojas citadas é apresentado no Quadro 7.
Considerando o total de entrevistados, esse valor cai para $6 \%$, o que mostra um valor inexpressivo para

Quadro 5 - Reconheceu o aroma na fase espontânea e já compraram na MMartan

\begin{tabular}{lcc}
\hline Alternativas & Frequência & $\%$ \\
\hline Sim & 15 & 88 \\
Não & 2 & 12 \\
Total & 17 & 100 \\
\hline
\end{tabular}

Fonte: Dados da pesquisa.

Quadro 6 - Associa o aroma a alguma dessas lojas (fase estimulada)

\begin{tabular}{lcc}
\hline Reconhece & Frequência & $\%$ \\
\hline Sim & 91 & 72 \\
Não & 35 & 28 \\
Total & 126 & 100 \\
\hline
\end{tabular}

Fonte: Dados da pesquisa.

Quadro 7 - Lojas citadas no Quadro 6

\begin{tabular}{lcc}
\hline Lojas & Frequência & $\%$ \\
\hline Renner & 19 & 21 \\
Skyler & 14 & 16 \\
Tentacion & 13 & 14 \\
Animale & 12 & 13 \\
MMartan & 9 & 10 \\
Liebe & 6 & 7 \\
Colcci & 5 & 6 \\
Americanas & 3 & 3 \\
Toli & 3 & 3 \\
Riachuelo & 2 & 2 \\
NS/NR & 5 & 100 \\
\hline Total & 91 & \\
\hline
\end{tabular}

Fonte: Dados da pesquisa. 
se considerar que o aroma gerou reconhecimento de marca, como identificado no Quadro 8.

Analisando a frequência com que vão à loja, os entrevistados que associaram corretamente o aroma na fase estimulada, obtém-se um número de sete pessoas para frequentaram e duas pessoas para não frequentaram (Quadro 9). Das que frequentaram, seis compraram nos últimos seis meses e apenas uma não comprou (Quadro 10).

Fazendo um comparativo entre alguns cortes na amostra total, iniciando por todos os 146 entrevistados, passando pelos 79 que conhecem a marca, os 36 que conhecem e frequentaram e por fim os 26 que conhecem, que frequentaram e compraram na MMartan, observa-se um aumento significativo de $20 \%$ para $81 \%$ referente aos que fizeram a correta associação do aroma à loja (Quadro 11).

Quadro 8 - Reconheceram o aroma na fase estimulada

\begin{tabular}{lcc}
\hline Alternativas & Frequência & $\%$ \\
\hline Sim & 9 & 6 \\
Não & 117 & 94 \\
Total & 126 & 100 \\
\hline
\end{tabular}

Fonte: Dados da pesquisa.

Quadro 9 - Reconheceu o aroma na fase estimulada e frequentou a loja MMartan

\begin{tabular}{lcc}
\hline Alternativas & Frequência & $\%$ \\
\hline Sim & 7 & 78 \\
Não & 2 & 22 \\
Total & 9 & 100 \\
\hline
\end{tabular}

Fonte: Dados da pesquisa.

Quadro 10 - Reconheceu o aroma na fase estimulada e já comprou na MMartan

\begin{tabular}{lcc}
\hline Alternativas & Frequência & $\%$ \\
\hline Sim & 6 & 86 \\
Não & 1 & 14 \\
Total & 7 & 100 \\
\hline
\end{tabular}

Fonte: Dados da pesquisa.
Por fim, com o intuito de avaliar a percepção dos entrevistados com relação às sensações remetidas a partir do aroma, tendo por base as variáveis originadas da entrevista aplicada com o proprietário da loja na fase qualitativa (tranquilidade, relaxamento e bem-estar), e do segundo pré-teste aplicado (elétrica, dor de cabeça e desconforto), obtiveram-se os resultados, mostrados no Quadro 12. Observou-se que as sensações pretendidas pelo proprietário para a loja são realmente as que mais são percebidas pelos consumidores (tranquilidade $-62 \%$, relaxamento $-59 \%$ e bem-estar - 34\%). Deve-se observar que, por essa ser uma questão de múltipla escolha, o percentual da soma dos sentimentos citados foi de $197 \%$.

Também foi levantada a questão sobre quais lembranças esse aroma evoca, tendo por base as variáveis fornecidas pelo proprietário (infância, seu lar e quarto de bebê), bem como a identificada no segundo pré-teste aplicado (adolescência). Como na questão anterior, o Quadro 13 mostra que as lembranças fornecidas pelo proprietário são as mais percebidas pelos entrevistados (seu lar - 38\%, quarto de bebê $14 \%$ e infância - 14\%).

\section{Conclusões}

A presente pesquisa apresenta os resultados obtidos a partir de um estudo composto por uma fase qualitativa exploratória e por outra quantitativa descritiva, tendo como problema verificar e analisar se a utilização da estratégia de marketing olfativo, aplicada em lojas de varejo, contribui para a geração de valor de marca. Para solucionar esse problema, a pesquisa objetivou investigar se o aroma, como componente integrante das marcas de varejo, gera valor de marca. 0 trabalho foi realizado tomando por base a suposição dos seguintes pressupostos:

I) 0 aroma estimula a lembrança espontânea da marca.

II) $\mathrm{O}$ aroma gera reconhecimento da marca de loja de varejo.

Por falta de parâmetros que possam auxiliar na análise e comparação dos dados obtidos, foi estabelecido o critério de que os percentuais de igual valor ou acima de $50 \%$ são considerados positivos para a pesquisa, assim como os abaixo desse valor são considerados negativos. 
Quadro 11 - Comparativo entres os cortes na amostra e que associaram corretamente o aroma

\begin{tabular}{|c|c|c|c|c|c|}
\hline & Conhece (79) & Frequentou (36) & Comprou (26) & $\begin{array}{c}\text { Conh/Freq/Comp. } \\
\text { (26) }\end{array}$ & Total (146) \\
\hline $\begin{array}{l}\text { Associou correta- } \\
\text { mente }\end{array}$ & 29 & 24 & 21 & 21 & 29 \\
\hline Total (\%) & 37 & 67 & 81 & 81 & 20 \\
\hline
\end{tabular}

Fonte: Dados da pesquisa.

Quadro 12 - Reconheceram o aroma (sensações)

\begin{tabular}{lcc}
\hline Lembranças & Frequência & $\%$ \\
\hline Adolescência & 3 & 10 \\
Nenhum & 3 & 10 \\
Quarto de bebê & 4 & 14 \\
Infância & 4 & 14 \\
Outros & 9 & 31 \\
Seu lar & 11 & 38 \\
Total & 29 & 117 \\
\hline
\end{tabular}

Fonte: Dados da pesquisa.

Assim, analisando o primeiro pressuposto, pode-se inferir que, a partir da amostra total pesquisada, que foi de 146 pessoas, o mesmo deve ser considerado como rejeitado, já que dos 82 entrevistados que, na fase espontânea, disseram reconhecer o aroma apresentado como sendo de alguma loja, apenas $25 \%$ fizeram a correta associação. Se for considerado o total da amostra, esse percentual cai para $20 \%$.

Contudo, se analisado por meio do corte feito na amostra inicial, considerando os 26 que conhecem e frequentam a loja, e compram na loja pesquisada, isto é, seus possíveis clientes, o percentual de pessoas que fizeram a correta associação vai para $81 \%$, isto é, mais da metade dos entrevistados. Assim, pode-se concluir que o primeiro pressuposto foi rejeitado parcialmente, ou seja, para a amostra de 146 entrevistados o aroma não pode ser considerado como um estimulador da lembrança de marca, porém, para os consumidores da MMartan, pode-se considerar que o aroma estimula sim a lembrança de marca.
Quadro 13 - Reconheceram o aroma (sensações)

\begin{tabular}{lcc}
\hline Aspectos & Frequência & $\%$ \\
\hline Tranquilidade & 18 & 62 \\
Relaxamento & 17 & 59 \\
Bem-Estar & 10 & 34 \\
Elétrica & 4 & 14 \\
Dor de Cabeça & 2 & 7 \\
Desconforto & 0 & 0 \\
Outros & 6 & 21 \\
NS/NR & 0 & 0 \\
Total & 29 & 197 \\
\hline
\end{tabular}

Fonte: Dados da pesquisa.

O segundo pressuposto, partindo da amostra geral de pessoas abordadas (146), não pôde ser considerado como confirmado, já que dos 91 entrevistados que disseram reconhecer o aroma apresentado como sendo de algumas das lojas mostradas no cartão, na fase estimulada, apenas $10 \%$ associaram corretamente. Com relação ao total de pessoas questionadas (146), esse percentual fica em $6 \%$.

Considerando o corte feito na amostra e que seleciona apenas os possíveis clientes da loja (26), o percentual de entrevistados que fizeram a correta associação na fase estimulada foi de $29 \%$, ou seja, menos da metade das pessoas que responderam à pesquisa nessa fase reconheceu a fragrância como sendo da MMartan, podendo concluir que o aroma também não gerou reconhecimento de marca. Logo, o segundo pressuposto foi negado em suas duas avaliações.

Sobre o comparativo entre as sensações e as lembranças levantadas pelo proprietário da loja como sendo o que ele espera ser percebido pelos consumidores 
através da estratégia de marketing olfativo aplicada na franquia da MMartan e o que realmente as pessoas percebem, pode-se considerar que o que é proposto é o que é percebido. Esse fato pode ser confirmado já que essas foram as sensações (tranquilidade, relaxamento e bem-estar) mais apresentadas como percebidas pelos entrevistados, tanto na amostra geral da pesquisa quanto no corte realizado.

Com as lembranças também não foi diferente, pois tanto as 146 pessoas abordadas quanto as 26 selecionadas posteriormente como clientes da loja consideraram remeter o aroma às emoções ou lembranças de seu lar, infância e quarto de bebê, assim como foi proposto pelo proprietário da MMartan.

Embora a presente pesquisa tenha apresentado dados que refletem negativamente a correta associação do aroma à marca na fase espontânea e para a totalidade da amostra, quando avaliado apenas os clientes da loja MMartan, pode-se inferir que o resultado foi positivo. Assim, no que diz respeito à lembrança espontânea de marca, o aroma pode e deve ser considerado um fator influenciador para aqueles que frequentam a loja e mantêm contato direto com a fragrância.

Já na fase estimulada, que buscou avaliar a relação entre a marca olfativa e o reconhecimento da marca, pode-se concluir que, para o total de entrevistados na pesquisa, o aroma não gerou reconhecimento, assim como para os possíveis clientes da loja estudada. Desta forma, a variável reconhecimento de marca foi negada em ambas as amostras analisadas.

Tendo por base que, no presente estudo, a variável lembrança de marca foi considerada parcialmente positiva e reconhecimento de marca foi negado em ambas as possibilidades, e partindo da premissa de que para se compreender o constructo valor de marca é preciso analisar individualmente os conceitos de lembrança e reconhecimento de marca, esta pesquisa mostra que não se pode concluir que o aroma, isto é, o marketing olfativo, possa ser considerado ainda uma estratégia influenciadora para a geração de valor de marca.

Talvez esse resultado possa ser justificado pelo fato desta ser uma pesquisa pioneira nos estudos da relação das variáveis aroma e valor de marca, não existindo assim comparativos que possam validar como positivo ou negativo os dados obtidos, além da recente introdução da estratégia de marketing olfativo no mercado, o que dificulta o seu manuseio pelos proprietários e gestores das lojas que a utilizam, bem como dificulta a percepção por parte, principalmente, dos não clientes da loja.
0 que se pôde perceber é que o aroma é um fator que estimula a lembrança de marca, em especial para aqueles que frequentam o ambiente de loja e mantêm contato com a fragrância, fato esse que não pode ser considerado para a variável reconhecimento de marca.

Assim, sugerem-se estudos futuros que possam realizar novas análises quanto à relação aroma e valor de marca, partindo das variáveis lembrança e reconhecimento de marca para outras lojas de varejo, a fim de se encontrar parâmetros de avaliação que possam ser comparados aos já encontrados.

Levando-se em consideração o bom resultado obtido para os entrevistados que conhecem, frequentam e compram na loja estudada, recomendam-se ainda pesquisas que avaliem o aroma como possível influenciador da atratividade da marca para os não clientes, impulsionando as compras.

\section{Referências}

CARNEIRO, J. V. C. Impacto dos estímulos olfativos nas decisões de compra. 2009. 103 f. Dissertação (Mestrado em Administração) - Universidade de Fortaleza, Fortaleza, 2009.

DAVIES, B. J.; KOOIJMAN, D.; WARD, P. The sweet smell of success: olfaction in retailing. Journal of Marketing Management, v. 19, n. 5/6, p. 611-627, 2003.

DONNICI, M. Olfato é estratégia para atrair consumidor: associar marcas a cheiros é mais uma ferramenta. 2005. Disponível em: <http://www.albertoclaro.pro.br/noticia. asp?codigo=875\&COD_MENU=82 >. Acesso em: 10 maio 2009.

FLÔR, P. P.; UMEDA, G. M. 0 marketing olfativo como aplicação do marketing experimental: uso de aromatizantes no varejo. In: CONGRESSO DE CIÊNCIA DA COMUNICAÇÃO NA REGIÃO SUDESTE, 13., 2008. São Paulo. Anais... São Paulo: INTERCOM. Disponível em: <http://www.intercom.org. br/papers/regionais/sudeste2008/resumos/R9-0271-1. pdf $>$. Acesso em: 10 maio 2009.

KELLER, K. L. Gestão estratégica de marcas. São Paulo: Pearson Prentice Hall, 2006.

LELO, M. V. et al. O retrato do estudo das práticas de marketing no Brasil. In: SEMINÁRIOS EM ADMINISTRAÇÃO FEA-USP, 10., 2007, São Paulo. Anais... São Paulo: SEMEAD, 2007. Disponível em: <http://www.ead.fea.usp. $\mathrm{br} /$ Semead/10semead/sistema/resultado/trabalhosPDF/437.pdf>. Acesso em: 10 maio 2009.

LINDSTROM, M. Brandsense: a marca multissensorial. Porto Alegre: Bookman, 2007. 
MALHOTRA, N. K. Pesquisa de marketing: uma orientação aplicada. Porto Alegre: Bookman, 2006.

MARKETING olfativo: que cheiro tem sua marca? Marketing, 2008. Disponível em: <http://www.marketing.com.br/index.php?option=com_content\&view $=$ ar ticle\&id=280: marketing-olfativo-que-cheiro-tem-sua-marca\&catid=38:mkt\&Itemid=82>. Acesso em: 24 jun. 2009.

MOORE, D. Olfactory stimulation and affect intensity: gender differences in yielding to the enticing aroma of food? Advances in Consumer Research, v. 31, n. 1, p. 603, 2004.

NUCCI, D. Fisgados pelo cheiro. Revista Metrópole, 2006. Disponível em: <http://www.cpopular.com.br/metropole/conteudo/mostra_noticia.asp?noticia $=1452273 \&$ area $=$ 2230\&authent $=546175633271225553745133432367>$. Acesso em: 3 jun. 2008.

NUNES, G.; HAIGH, D. Marca: valor do intangível, medindo e gerenciando seu valor econômico. São Paulo: Atlas, 2003.

OLIVEIRA, D. F. de. Mensurando o valor da marca, a reputação e a identidade no setor automotivo. 2006. $156 \mathrm{f}$. Dissertação (Mestrado em Administração) - Universidade Federal de Minas Gerais, Belo Horizonte, 2006.

PEREZ, E. Marketing olfativo. Portal do Marketing, 2007. Disponível em: <http://www.portaldomarketing.com.br/ Artigos/Marketing_olfativo.htm>. Acesso em: 3 jun. 2008.

SALAZAR, V. S.; FARIAS, S. A. de. Atmosfera de serviços em restaurantes gastronômicos: influências hedônicas na satisfação do consumidor. In: ASSOCIAÇÃO NACIONAL DE PÓS-GRADUAÇÃO E PESQUISA EM ADMINISATRAÇÃO, 30., 2006, Salvador. Anais... Salvador: EnANPAD, 2006.
SCHMITT, B. H.; SIMONSOM, A. A estética do marketing: como criar e administrar sua marca, imagem e identidade. São Paulo: Nobel, 2002.

SCHMITT, B. H. Marketing experimental. São Paulo: Nobel, 2002.

SERRALVO, F. A. (Org.). Gestão de marcas no contexto brasileiro. São Paulo: Saraiva, 2008.

SIMÕES, K. Aromas que vendem. Pequenas Empresas \& Grandes Negócios, 2008. Disponível em: <http://empresas.globo.com/Empresasenegocios/0,19125,E RA463263-2491,00.html>. Acesso em: 3 jun. 2008.

TAVARES, M. C. Gestão de marcas: construindo marcas de valor. São Paulo: Harbra, 2008.

ZAREM, J. E. Experience marketing. The Magazine for Magazine Management, v. 1, n. 3, p. 28-32, 2000.

Recebido: 26/09/2011

Received: 09/26/2011

Aprovado: 18/10/2011

Approved: 10/18/2011 